\title{
MOROSIDADE DO PODER JUDICIÁRIO: PRIORIDADES PARA A REFORMA
}

\section{THE SLOWNESS OF THE JUDICIARY: PRIORITIES FOR REFORM}

Vera Lúcia Feil Ponciano"

\begin{abstract}
Resumo: Aborda sobre a explosão de litigiosidade ocorrida no Brasil a partir da atual Constituição Federal, que levou ao ponto culminante o problema da morosidade da prestação jurisdicional. Enfatiza o despertar da sociedade brasileira para a realidade da estrutura do sistema judicial, que gerou a necessidade de reforma do Judiciário. Destaca reformas legislativas efetuadas. Elenca algumas prioridades para a consecução da almejada reforma do Poder Judiciário.

Palavras-chave: Litigiosidade. Morosidade. Crise. Poder Judiciário. Reforma.

Abstract: The text treats about the increase of the litigation in Brazil after the current Constitution and, as a consequence, the slowness of the Judicial process in Brazil. It emphasizes the awakening of the brazilian society to the deficiencies of the law system structure, which caused the need of a Judiciary Reform. Criticizes the speeches that cause an overall feeling of a Judiciary crisis, without showing technical studies or viable solutions. Gives attention to the law changes. Points some priorities to put in practice the desired Judiciary Reform.
\end{abstract}

Keywords: Litigation. Slowness of the Judicial process. Crisis. Judiciary. Reform.

\section{INTRODUÇÃO}

A questão da necessidade de reforma do Poder Judiciário tem sido colocada no centro dos debates jurídicos, políticos e sociais, principalmente a partir da Constituição Federal de 1988, pelo fato de esta ter contribuído para o surgimento

"Juíza Federal da $8^{\circ}$ Vara Cível de Curitiba/PR, mestranda em Direito Econômico e Socioambiental na Pontifícia Universidade Católica do Paraná (PUC/PR). email: vlp@jfpr.gov.br. 
de várias demandas sociais reprimidas e ampliação do acesso à justiça, gerando o protagonismo do Poder Judiciário. No entanto, este não estava preparado para cumprir sua função de pacificação social por meio da resolução dos conflitos de modo célere e adequado.

Esse fato, aliado à dinâmica do mundo moderno, proporcionada pela evolução tecnológica e científica, despertou a sociedade brasileira para a realidade da estrutura do sistema judicial, tida como arcaica, burocrática e ineficiente, especialmente em virtude da morosidade da prestação jurisdicional.

Diante desse quadro, cresceu a insatisfação social com esse Poder, e passou a ser destacada a existência de uma "crise" do Poder Judiciário. Embora a morosidade seja um grave problema a ser solucionado, a sensação de "crise" é explorada politicamente, e muitos discursos que pregam a reforma do Judiciário são desprovidos de estudos técnicos e científicos, no que tange aos diagnósticos e à previsão de soluções.

O objetivo deste artigo é indicar prioridades para a reforma do Judiciário, relacionadas à democratização do acesso à justiça; ao investimento em recursos humanos, tecnológicos e materiais; à identificação dos fatores que causam a morosidade e à necessidade de um planejamento estratégico em nível nacional.

\section{A EXPLOSÃO DE LITIGIOSIDADE}

$\mathrm{Na}$ área da ciência e tecnologia, o século passado, sobretudo após a II Guerra Mundial, foi marcado por um progresso sem precedentes na história da humanidade, em virtude de novas descobertas científicas e do surgimento de inovações tecnológicas, todas destinadas a proporcionar, em tese, mais satisfação e felicidade ao ser humano. Esse progresso proporcionou um mundo cada vez mais dinâmico, no qual as relações comerciais se desenvolvem de modo célere e em tempo real.

Esse progresso proporcionou um mundo cada vez mais dinâmico, no qual as relações comerciais se desenvolvem de modo célere e em tempo real.

$\mathrm{Na}$ área do direito a revolução, a partir do mesmo período, ficou por conta do reconhecimento dos direitos humanos em nível internacional pela Declaração Universal dos Direitos Humanos de 10/12/1948; pelos demais tratados e convenções posteriores; pela inclusão de novos direitos na Constituição de vários países ocidentais, o que fez Norberto Bobbio qualificar a era após II Grande Guerra como a Era dos Direitos (BOBBIO, 1992).

No plano lógico-formal, a Constituição Federal de 1988 não ignorou essas transformações, contribuindo para a democratização do país e para o surgimento 
Morosidade do Pode Judiciário: prioridades para a reforma

de uma sociedade mais consciente e preocupada com as questões da cidadania e com o acesso à justiça, considerando a ampliação do rol dos direitos fundamentais, com ênfase especial aos de terceira geração ${ }^{1}$.

Esse progresso no campo jurídico-constitucional brasileiro gerou expectativas crescentes de efetivação daqueles direitos pelo Estado, a fim de garantir-se a igualdade material. Todavia, o Brasil não estava dotado de condições para tanto, motivo pelo qual as expectativas se voltaram para o Poder Judiciário, que passou a ser provocado para garantir os direitos consagrados na atual Lei Fundamental.

Diante desse quadro, surgiram novas formas de conflito e abriu-se caminho para o acesso à justiça de várias demandas sociais até então reprimidas, o que contribuiu para o protagonismo do Judiciário e, conseqüentemente, para o aumento da quantidade de processos, o que se convencionou chamar "explosão de litigiosidade", que tivera seu marco inicial a partir da década de $70^{2}$, conforme disserta José Eduardo Faria (FARIA, 2003, p. 6):

Por isso, desde que um amplo espectro de movimentos sociais - centros de defesa de direitos humanos, comunidades de base, comissões eclesiais de base, movimentos de minorias, sindicatos, organizações não-governamentais, etc. - emergiu entre os anos 70 e 80 procurando ampliar o acesso dos segmentos marginalizados e pobres da população à Justiça, e o advento da Constituição de 88 propiciou um sem número de demandas judiciais para o reconhecimento de novos direitos (moradia) e a aplicação de direitos já consagrados (reforma agrária), os tribunais brasileiros passaram a movimentar toneladas de papel e a protocolar, carimbar, rubricar, distribuir, despachar e julgar milhões de ações (Quadro 4).

Boaventura de Souza Santos (SANTOS, 1997, p. 44) enfatiza sobre o assunto:

De tudo isto resultou uma explosão de litigiosidade à qual a administração da justiça dificilmente poderia dar resposta. Acresce que esta explosão veio a agravar-se no início da década de 70, ou seja, num período em que a expansão econômica terminava e se iniciava uma recessão que se prolonga até hoje e que, pela sua pertinácia, assume um caráter estrutural. Daí resultou a redução progressiva dos recursos financeiros do

${ }^{1} \mathrm{O}$ ideal de fraternidade corresponde à terceira geração dos direitos fundamentais, ou seja, a outras modalidades de direitos decorrentes de uma sociedade de massa, surgida em razão dos processos de industrialização e urbanização, tais como desenvolvimento, paz, meio ambiente, saúde, educação pública, proteção ao consumidor, à infância e à juventude, ao idoso e ao deficiente físico.

${ }^{2}$ De acordo com a pesquisa realizada no Banco Nacional de Dados do Poder Judiciário, apurou-se que o número de feitos ajuizados no ano de 2000 foi superior em 135\% ao total ajuizado em 1990. 
Estado e sua crescente incapacidade para dar cumprimento aos compromissos assistenciais e providenciais assumidos para com as classes populares da década anterior.

Entretanto, o Judiciário não estava preparado para responder com efetividade a essa explosão de litigiosidade. Assim, ao mesmo tempo em que se evidenciou o protagonismo do Judiciário, cresceu a insatisfação social com esse Poder, pois ele não estava - e ainda não está - dotado de condições para atender a essa crescente demanda, seja por deficiência na área de recursos humanos ${ }^{3}$, tecnológicos ou materiais.

Entretanto, não podemos ignorar outros fatores que colaboraram para a explosão de litigiosidade. Entre eles, podemos destacar: a) o avançado progresso da tecnologia de informação, que contribuiu para que as pessoas passassem a ser mais bem informadas sobre seus direitos inclusive; b) a disparidade gravíssima entre o discurso jurídico e a planificação econômica (ZAFFARONI, 1995, p. 24); c) a judicialização da política e da economia, que é um fenômeno complexo e envolve vários fatores (FARIA, 2003, p. 12) 4 $^{4}$ d) a instabilidade normativa e a “inflação jurídica” (FARIA, 2003, p. 14), decorrente da produção legislativa de forma desordenada e desenfreada, inclusive contrariando a Constituição Federal e leis infraconstitucionais; e) o aumento da burocracia estatal e a produção legislativa impulsionada unicamente pelo clientelismo político (ZAFFARONI, 1995, p. 25); f) não implantação pelo Estado brasileiro das políticas públicas necessárias à efetivação dos direitos garantidos pela atual Carta Magna.

Tais fatores demonstram, em verdade, a "crise" do Estado brasileiro, que desobedece à própria Constituição e não garante os direitos que estão previstos nela. A litigiosidade no nosso país cresce dia a dia, exigindo esforços por parte do número reduzido de juízes e servidores, que não conseguem dar conta da crescente demanda, não obstante as constantes reformas legislativas e a existência dos recursos tecnológicos disponíveis.

De qualquer modo, é importante que a sociedade brasileira tenha despertado para a questão da democratização do acesso à justiça e da eficiência do Poder Judiciário, especialmente no tocante à morosidade ${ }^{5}$, passando a exigir que a

${ }^{3}$ Importante frisar que os recursos humanos em alguns órgãos do Poder Judiciário deixam a desejar tanto em termos de quantidade quanto no aspecto da qualificação de servidores.

${ }^{4}$ Segundo José Eduardo Faria, um dos fatores é "a incapacidade do Estado de controlar, disciplinar e regular, com os instrumentos normativos de um ordenamento jurídico resultante de um sistema romano idealista, rígido e sem vínculos com a realidade contemporânea, mercados cada vez mais integrados em escala planetária”. 
Morosidade do Pode Judiciário: prioridades para a reforma

atividade jurisdicional acompanhe a dinâmica do mundo moderno, a fim de atender às necessidades sociais emergentes numa nova ordem democrática, considerando a sua função social e a importância da justiça no Estado Democrático de Direito contemporâneo.

\section{A MOROSIDADE DA PRESTAÇÃO JURISDICIONAL}

Diante dessa alta litigiosidade e da insatisfação social, o Judiciário não podia permanecer fechado em si mesmo e incapaz de se auto-avaliar, tampouco o Poder Legislativo e Executivo poderiam ficar alheios ao problema. Em virtude disso, os três poderes passaram a discutir abertamente a questão ${ }^{6}$, bem como juristas e a sociedade interessada numa prestação jurisdicional célere e eficiente, pois se tornou inconcebível que o Poder Judiciário mantenha sua estrutura atual e fique alheio às transformações sociais e aos novos conflitos. Indubitavelmente, a morosidade do Judiciário é realidade e a necessidade de combatê-la é premente.

Em 1997, o Banco Mundial, dentro do seu programa de estudos acerca do Judiciário dos países da América Latina, iniciado na década de 80, elaborou o relatório O Setor Judicial na América Latina e no Caribe: Elementos da Reforma DALOKIAS, 1996, p. 6-10). Entre as constatações do estudo técnico realizado, podemos destacar as seguintes:

"o Judiciário é incapaz de assegurar a resolução de conflitos de forma previsível e eficaz, garantindo assim os direitos individuais e de propriedade"; "a reforma do Judiciário faz parte de um processo de redefinição do Estado e suas relações com a sociedade, sendo que o desenvolvimento econômico não pode continuar sem um efetivo reforço, definição e interpretação dos direitos e garantias sobre a propriedade. Mais especificamente, a reforma do judiciário tem como alvo o aumento da eficiência e equidade em solver disputas, aprimorando o acesso à justiça que atualmente não tem promovido o desenvolvimento do setor privado".

${ }^{5}$ Conforme consta na edição especial da revista Consulex n ${ }^{\underline{a}}$ 167, de dezembro de 2003, p. 17, em pesquisa promovida, os advogados indicaram como um dos principais problemas da Justiça a morosidade. Também foi promovida pesquisa entre os juízes em 1993 pelo Instituto de Estudos Econômicos, Sociais e Políticos de São Paulo (IDESP), tendo sido apontada a morosidade como um dos principais problemas do Judiciário.

${ }^{6}$ Em 15 de dezembro de 2004 o Presidente da República, o Presidente do STF, o Presidente do Senado Federal e o Presidente da Câmara dos Deputados firmaram o Pacto de Estado em favor de um Judiciário mais rápido e republicano (http:// www.mj.gov.br/reforma/pdf/publicacoes/Reforma_do_judiciario.pdf). 
Embora a ênfase do estudo seja na "modernização do Poder Judiciário para assegurar um ambiente tranqüilo aos investimentos estrangeiros, por meio do cumprimento dos contratos, da certeza e previsibilidade dos direitos sobre a propriedade", não havendo "qualquer vinculação direta entre o financiamento para a reforma e a melhoria das condições sociais desses países”, sendo a razão maior para a modernização "garantir aos investidores estrangeiros em países emergentes, o rendimento "compatível" com o risco de se investir nesses países" (BARBOSA, 2007, p. 3) o maior para a modernizaçnto para a reforma e a melhoria das condiçs, da certeza e privisibilidade dos direitos sobre a proprie ${ }^{7}$, não há dúvidas de que o documento do Banco Mundial colaborou para acelerar os debates e dar início a um processo de reforma do Poder Judiciário, inclusive em nível constitucional.

Todavia, muitos debates instaurados sobre a morosidade do Poder Judiciário e a necessidade de sua reforma, sem base em estudos técnicos e estatísticas, acabam passando uma generalizada sensação de "crise" judicial, como se a morosidade do Judiciário nunca tivesse existido. Ao contrário, a história demonstra que a justiça brasileira sempre foi morosa e distanciada da população, ou seja, estar em "crise" atualmente pressupõe que um dia a justiça brasileira tenha sido célere e democrática (TASSE, 2004, p. 43).

Destarte, o debate não pode ser exagerado nem generalizado ou baseado em meras opiniões pessoais, pois se "crise" do Judiciário existe, não decorre ela apenas da ineficácia do Judiciário em dar solução rápida às demandas, mas de várias causas, inclusive relacionadas à crise do próprio modelo de Estado, que geraram um crescente protagonismo do Judiciário no seio de uma sociedade desigual (FARIA, 2003, p. 15).

\section{A REFORMA CONSTITUCIONAL E INFRACONSTITUCIONAL}

A Emenda Constitucional n⿳a 45/2004 promoveu a almejada Reforma do Judiciário, trazendo diversas mudanças com o objetivo de tornar o Poder Judiciário mais transparente e a prestação jurisdicional eficaz e célere. Entre as mudanças, podem ser citadas a instituição da garantia da razoável duração do processo ${ }^{8}$, a quarentena dos juízes9 , a criação do Conselho Nacional de Justiça (CF, art. 92, I-

\footnotetext{
${ }^{7}$ Projeto de Pesquisa BRA/07/004 - Pensando o Direito, apresentado Ministério da Justiça - Secretaria de Assuntos Legislativos - SAL. Programa das Nações Unidas para o Desenvolvimento - PNUD. ÁREA TEMÁTICA: Observatório do Poder Judiciário. TÍTULO DO PROJETO: Novos parâmetros para a construção de um Poder Judiciário realizador do Estado Democrático de Direito. Junho 2007.
} 
Morosidade do Pode Judiciário: prioridades para a reforma

A), a adoção da Súmula Vinculante (CF, art. 103-A) e a ampliação da competência da Justiça do Trabalho (art. 114).

Após a EC n 45/2004 iniciou-se o processo de reforma da legislação infraconstitucional, com o objetivo também de encontrar solução para a lentidão do sistema judiciário. Várias alterações foram feitas, por exemplo, no Código de Processo Civil, entre elas, pelas Leis $\mathrm{n}^{\underline{a}} \mathrm{~s} 1.187$, de $19.10 .2005 ; 11.232$, de 22.12.2005; 11.276/06; 11.280/06 11.382/06; 11.419/06 e 11.448/07. No entanto, tais reformas não têm sido suficientes para resolver o problema da morosidade.

Desse modo, a discussão vai além da necessidade de meras reformas constitucionais e legais isoladas. A redução da litigiosidade e a resolução dos conflitos de modo célere e adequado não são possíveis apenas com reformas processuais, motivo pelo qual é preciso pensar em outras medidas que possam colaborar para a solução do problema.

\section{PRIORIDADES PARA A REFORMA DO JUDICIÁRIO}

\subsection{Redução do valor das custas processuais}

Uma mudança que contribuiria para a democratização do acesso à justiça é a redução do valor das custas processuais, além da uniformização delas em nível nacional, pois, sem dúvida, em muitos Estados da Federação, no âmbito da Justiça Estadual, o valor delas é tão elevado que impede o indivíduo de ingressar perante o Judiciário. Observa-se ainda que aos processos que contam com a assistência judiciária gratuita não é dispensado o mesmo tratamento que àqueles em que as custas são pagas.

Tomamos as lições de Adel El Tasse (TASSE, 2004, p. 40, 81) para amparar nossa afirmação, dada a ousadia e coragem com que enfrentou o assunto, verbis:

"O acesso jurisdicional, como garantia constitucional não passa, em muitos Estados brasileiros, de ilusão, posto que a Justiça é cara, em sistemas cartorários arcaicos, segundo os quais os serviços inerentes ao Poder Público pertencem à iniciativa privada.

${ }^{8}$ A EC n⿳a 45/2004 introduziu o inciso LXXVIII no art. 5ª , preconizando que: "LXXVIII - a todos, no âmbito judicial e administrativo, são assegurados a razoável duração do processo e os meios que garantam a celeridade de sua tramitação”.

${ }^{9}$ É proibido ao magistrado exercer a advocacia no juízo ou tribunal do qual se afastou, antes de decorridos três anos do afastamento do cargo por aposentadoria ou exoneração (CF, art. 95, V). 
Vera Lúcia Feil Ponciano

A prestação jurisdicional é obstada, em várias hipóteses, pelas elevadas custas que, na esperança que ao final seu direito seja reconhecido, deve a parte arcar em proveito do enriquecimento dos titulares de cartórios privados.

"A realidade é que as portas da justiça estão cerradas para a grande maioria da população brasileira, que suporta as dores de ver seu direito sacrificado".

"Não se pode perder de vista, igualmente, os custos da justiça brasileira, que não permitem que as camadas menos favorecidas economicamente possam obter a tutela do Poder Judiciário, para o resguardo de seus direitos.

"Em muitos Estados brasileiros, como no caso do Paraná, ainda é mantida uma arcaica ditadura cartorária, na qual cartórios judiciais não pertencem ao Estado. $\mathrm{O}$ objetivo de toda estrutura judicial é a pacificação social, no entanto, tais cartórios não passam de meras máquinas de "fazer dinheiro" para seus proprietários que, em geral, não apresentam preocupações com o cessar da litigiosidade na sociedade, atuando, tão-somente, na contínua batalha pelo aumento de seus lucros”.

Não obstante o elevado valor das custas processuais, a qualidade do serviço prestado deixa a desejar, pois não há investimento adequado em recursos humanos - quantitativamente e qualitativamente -, tampouco em recursos tecnológicos e materiais.

Essa constatação não se baseia em mera opinião pessoal, pois a Ordem dos Advogados do Brasil - OAB/PR, em seu Jornal da Ordem, do mês de junho de 2007, estampou na primeira página a seguinte notícia: "Varas Estaduais - Retrato do caos na Justiça do Paraná”, destacando: a) a falta de varas e de juízes, que compromete o funcionamento da Justiça; b) a falta de equipamentos de informática; c) o despreparo de juízes e serventuários; d) a morosidade, inclusive para efetuar uma simples consulta do andamento processual.

$\mathrm{Na}$ reportagem e nas opiniões colhidas destacam-se expressões tais como: "É o caos!"; "A solução não pode mais ser adiada. A situação é absolutamente insuportável"; "falta ordem na casa"; "Estamos num declive imenso e não sabemos aonde vamor parar"; "situação absurda"; "Só o tempo que levamos para fazer uma simples consulta demonstra o quanto estamos sendo desrespeitados"; "A maioria das cidades do interior do Paraná também vive a dramática deteriorização da Justiça Comum Estadual"; "A situação é de colapso".

Embora as constatações se refiram a toda a Justiça Estadual de $1^{\circ}$ instância, envolvendo cartórios oficiais (criminais, criança e adolescente), a maior cobrança para que o serviço seja prestado de forma célere e adequada deve ser feita aos cartórios não oficiais, pois estes é que cobram custas elevadas e auferem lucro. Conforme expressão do advogado Newton de Sisti no periódico referido: "Os 
Morosidade do Pode Judiciário: prioridades para a reforma

cartórios precisam ser oficializados para que não se tenha a ambição do lucro ao gerenciá-los".

Desse modo, é necessário que os administradores do Poder Judiciário Estadual atentem para essa realidade nos Estados em que a estrutura judicial esteja na situação analisada, não obstante a resolução do problema envolva questões políticas também.

\subsection{Recursos humanos, tecnológicos e materiais}

Para que o Judiciário possa prestar a tutela jurisdicional de forma adequada, célere e com qualidade, sem dúvida deve existir número suficiente de juizes e de servidores, além do necessário investimento em recursos tecnológicos e materiais.

No tocante ao número reduzido de juízes, o Min. Sálvio de Figueiredo Teixeira (TEIXEIRA, 2001, p. 4), no ano de 2001, salientou que tínhamos 01 para cada 25 a 29 mil habitantes, verbis:

Dessa moldura se conclui, sem maiores esforços, que há uma nítida distinção entre o Judiciário que a sociedade reclama, e todos desejamos, e o Judiciário que aí está posto, que a todos descontenta, inclusive, e, sobretudo, aos juízes, em quem acabam por recair as críticas generalizadas, desconhecendo os jurisdicionados a real dimensão da problemática, quando temos 1(um) juiz para cada 25 a 29 mil habitantes(a média, na Europa, é de 1 para 7.000 a 10.000), quando o Supremo Tribunal Federal julga mais de 100.000(cem mil) processos por ano(enquanto a Suprema Corte dos Estados Unidos julga menos de 100 (cem) causas em igual período) e o Superior Tribunal de Justiça mais de 200.000(duzentos mil), com um aumento anual de aproximadamente $20 \%$, números de longe sem similar no plano internacional, sendo de acrescentar que igualmente supercongestionadas estão às instâncias ordinárias.

Todavia, frisamos que não apenas deve ser aumentado o número de juízes, como também ser dada ênfase a um processo de formação e aperfeiçoamento dos magistrados, por intermédio da Escola Nacional da Magistratura, prevista no art. 93, inc. IV, da CF, segundo o qual essa Escola deve ser responsável pela "previsão de cursos oficiais de preparação, aperfeiçoamento e promoção de magistrados, constituindo etapa obrigatória do processo de vitaliciamento a participação em curso oficial ou reconhecido por escola nacional de formação e aperfeiçoamento de magistrados”.

Visando cumprir o mandamento constitucional, foi instituída a Escola Nacional de Formação e Aperfeiçoamento de Magistrados (ENFAM), por meio da 
Vera Lúcia Feil Ponciano

Resolução $\mathrm{n}^{\mathrm{a}}$ 03, de 30.11.2006, da Presidência do STJ - Superior Tribunal de Justiça, com o objetivo de regulamentar, autorizar e fiscalizar os cursos oficiais para ingresso e promoção na carreira da Magistratura (art. 1aㅡ).

Compreendem-se no objetivo as seguintes atividades: a) definir as diretrizes básicas para a formação e o aperfeiçoamento de Magistrados; b) fomentar pesquisas, estudos e debates sobre temas relevantes para o aprimoramento dos serviços judiciários e da prestação jurisdicional; c) promover a cooperação com entidades nacionais e estrangeiras ligadas ao ensino, pesquisa e extensão; d) incentivar o intercâmbio entre a Justiça brasileira e as de outros países; e) estimular, diretamente ou mediante convênio, a realização de cursos relacionados com o objetivo da ENFAM, dando ênfase à formação humanística; f) habilitar para os efeitos do art. 93, inciso II, alínea "c", e inciso IV, da Constituição Federal, cursos de formação e aperfeiçoamento de magistrados oferecidos por instituições públicas ou privadas.

Dirigido pelo presidente do Superior Tribunal de Justiça, ministro Raphael de Barros Monteiro Filho, o Conselho Superior da ENFAM é integrado pelos membros do Conselho de Administração do Tribunal e por dois magistrados de segundo grau designados pela Associação dos Magistrados Brasileiros (AMB) e pela Associação dos Juízes Federais do Brasil (AJUFE).

Os cursos oferecidos pela ENFAM serão divididos da seguinte forma: curso de formação para ingresso na magistratura e curso de aperfeiçoamento dos magistrados, visando ao vitaliciamento e ao constante aprimoramento necessário à promoção do juiz e ao exercício da jurisdição.

O curso de formação de magistrados fará parte da última etapa do concurso público para ingresso na carreira, terá a duração mínima de quatro meses e o candidato receberá uma bolsa mensal de valor mínimo equivalente a $50 \%$ da remuneração do juiz substituto. A obrigatoriedade do curso de formação é a primeira inovação instituída pela Escola Nacional de Formação e Aperfeiçoamento da Magistratura e foi aprovada pelos representantes das 33 escolas estaduais e federais de magistratura reunidos no Superior Tribunal de Justiça.

Outra inovação aprovada foi à instituição do curso de aperfeiçoamento para que o magistrado obtenha a vitaliciedade do cargo. Atualmente, ela é concedida após dois anos de exercício na magistratura, sem a necessidade de qualquer tipo de aperfeiçoamento. A partir de agora, no decorrer dos dois anos de exercício, o magistrado participará de pelo menos 120 horas de cursos - 30 horas por semestre. Os cursos para efeito de promoção terão duração mínima de 20 horas por semestre e serão específicos para cada promoção (ENFAM, 2007). 
Morosidade do Pode Judiciário: prioridades para a reforma

O Conselho da Justiça Federal (CJF) também instituiu o Plano Nacional de Aperfeiçoamento e Pesquisa para Juízes Federais ${ }^{10}$ (PNA), aprovado em 31/08/ 2007. O fundamento é que juízes com conhecimento nas áreas de sociologia, filosofia, política, entre outras relevantes à realidade atual, além do especificamente técnico-jurídico, garante um Judiciário mais condizente com as necessidades e anseios da sociedade moderna. Essa premissa é a base do pensamento que moveu a criação do Conselho das Escolas de Magistratura Federal (CEMAF) e a elaboração do Plano Nacional de Aperfeiçoamento e Pesquisa para Juízes Federais, previsto na Resolução $\mathrm{n}^{\mathrm{a}}$ 532. de 20.11.2006. O plano, para o biênio 2008/ 2010, foi aprovado pelos membros do CEMAF, em 20.08.2007, em reunião realizada na Coordenação- Geral da Justiça Federal.

O Plano compreende as bases políticas, metodológicas e operacionais para seleção, formação, aperfeiçoamento e especialização dos juízes federais. A meta para 2008 e 2009 é de que 100\% dos concursos públicos para o ingresso na carreira de juiz federal substituto sejam realizados de acordo com o conteúdo programático proposto no Programa. O PNA será encaminhado para o Conselho da Justiça Federal, para apreciação pelo seu Colegiado.

A implementação do Plano será de responsabilidade do Centro de Estudos Judiciários do Conselho da Justiça Federal (CEJ/CJF), como órgão central de sistema, e das Escolas de Magistratura Federais dos Tribunais Regionais Federais. A avaliação e monitoramento do programa ficará a cargo do CEMAF, com o auxílio do CEJ/CJF, que elaborará o sistema com objetivos, metas e indicadores previamente definidos. As escolas programarão as ações previstas no PNA até o mês de setembro anterior ao biênio de execução, encaminhando o currículo de cursos ao CEMAF.

O Min. Sálvio de Figueiredo Teixeira (TEIXEIRA, 2001, p. 5) já defendia a existência de uma escola judicial institucionalizada de âmbito nacional (grifo original):

Além do vazio de poder que se reflete na multiplicidade de vozes que "acham" isso e aquilo, enquanto a própria sociedade não sabe qual o modelo que o Judiciário deseja e que alternativas oferece, vê-se que, não obstante a iniciativa do Executivo brasileiro há mais de 20(vinte) anos, e a extraordinária evolução que está ocorrendo em todo o mundo, a propósito da seleção, formação e aperfeiçoamento dos juízes, até hoje o Brasil não conta com uma escola judicial institucionalizada de âmbito nacional, o que ganha maior destaque quando se sabe que os estudiosos têm apontado tais escolas como o maior fenômeno positivo surgido no Judiciário na segunda metade do século $X X$.

${ }^{10}$ Conforme informações do sítio http://www.jf.gov.br/portal/publicacao/engine. wsp?tmp. area $=83 \&$ tmp.texto=10131. Aacesso em: 30 agosto 2007. 
Vera Lúcia Feil Ponciano

A reforma do Judiciário: reflexões e prioridades E não poderia ser diferente. Se o Judiciário se torna essencial à convivência social, se o seu papel será cada vez mais importante neste século XXI, somente com juízes à altura dessa missão teremos o Judiciário que se pretende e com o qual todos sonhamos. Destarte, sobretudo quando cada vez mais jovens são os novos juízes* no mundo do Civil Law, quando os sistemas jurídicos passam por profundas mudanças legislativas e uma nova mentalidade se reclama, torna-se imprescindível a adoção de boas escolas, nos moldes das ricas e admiráveis experiências que o mundo civilizado vem presenciando.

Portanto, considerando que um dos maiores desafios para o Poder Judiciário é selecionar e formar bons magistrados, devidamente preparados a solucionar os conflitos de interesses de forma célere e justa, não resta dúvidas de que são necessárias mudanças para possibilitar uma boa seleção, formação e aperfeiçoamento do magistrado.

No que tange aos recursos tecnológicos e materiais, ao lado das reformas processuais introduzidas pelas leis e de outras mudanças necessárias, é preciso que o Poder Judiciário invista na modernização de sua gestão, incorporando aos seus serviços as ferramentas tecnológicas disponíveis no mercado, com a finalidade de alcançar agilidade e eficiência na prestação jurisdicional.

A modernização do Poder Judiciário já se iniciou, embora não de modo uniforme em toda a justiça brasileira. A plataforma eletrônica, aliada à qualificação dos recursos humanos, poderá tornar-se o instrumento pelo qual se alcançará celeridade e eficiência na prestação jurisdicional, no que se refere, por exemplo, à redução do lapso temporal de recebimento, envio de informações e consultas a outros órgãos, operando-se através de sistemas integrados de base de dados.

A utilização das tecnologias viabiliza uma racionalização e facilitação de procedimentos dos serviços judiciários, auxiliando na ampliação do acesso à justiça e à celeridade processual. A informatização e a Internet possibilitaram, por exemplo, a prestação de vários serviços, entre eles: páginas eletrônicas; comunicação eletrônica dos atos processuais; diário da justiça eletrônico ${ }^{11}$; disponibilidade de inteiro teor de acórdãos, sentenças e decisões na internet; consulta do andamento processual na internet; envio de petições por correio

${ }^{11}$ Em 16 de abril de 2007, o Supremo Tribunal Federal lançou, por meio da Resolução n⿳a 341 da Presidência, o Diário da Justiça Eletrônico, uma versão digital da publicação oficial que reúne todos os atos processuais do Tribunal. Esse Diário substitui a versão impressa das publicações oficiais e passa a ser veiculado gratuitamente na rede mundial de computadores - Internet.

${ }^{12}$ A Lei n ${ }^{\underline{a}}$ 11.419/2006 não exige a entrega da petição em papel posteriormente. A Lei autoriza o envio de petições, de recursos e a prática de atos processuais em geral por meio eletrônico mediante uso de assinatura eletrônica 
Morosidade do Pode Judiciário: prioridades para a reforma

eletrônico ${ }^{12}$; acesso pelo magistrado das Declarações de Bens e Direitos no sítio da Receita Federal, mediante certificação digital ${ }^{13}$; Sistema BACEN-JUD ${ }^{14}$; processo eletrônico (e-proc) ${ }^{15}$.

O Relatório Anual do Conselho Nacional de Justiça (CNJ, 2006, p. 3 ) ${ }^{16}$ destaca a importância do uso das ferramentas tecnológicas:

O uso intensivo da informatização é indispensável para a aceleração de procedimentos. Quase todos os tribunais já contam com um razoável parque informático, embora os equipamentos se encontrem isolados por problemas de conectividade e de operacionalidade que podem ser solucionados. O grande desafio consiste na quebra dos paradigmas tradicionais de utilização dos recursos disponíveis. Normalmente, os computadores são empregados para pouco mais que edição de textos, e a conexão internet, para consulta a repositórios de jurisprudência. As possibilidades da tecnologia da informação como meio de aceleração da tramitação processual precisam ser demonstradas para juízes, legisladores, funcionários e usuários a fim de que compreendam que é possível obter segurança e permanência nos registros sem o suporte papel.

Com efeito, o uso intensivo dos recursos tecnológicos no sistema judiciário

${ }^{13}$ A Secretaria da Receita Federal do Brasil adotou o Certificado Digital para que os serviços protegidos por sigilo fiscal também possam ser atendidos por meio de sua página na Internet, com o objetivo de certificar a autenticidade dos emissores e destinatários dos documentos eletrônicos, assegurando sua privacidade e inviolabilidade. Assim, foi possível a esse órgão também criar o Sistema INFOJUD (Informações ao Judiciário), por meio do qual possibilita aos magistrados acesso online aos dados cadastrais (CPF e CNPJ) e declarações de pessoas físicas (DIRPF e DITR) e jurídicas (DIPJ, PJ Simplificada e DITR).

${ }^{14}$ Sistema criado pelo Banco Central do Brasil, por meio do qual se permite a solicitação de informações de dados protegidos por sigilo bancário, envolvendo pessoas físicas e jurídicas clientes do Sistema Financeiro Nacional, sobre a existência de contas correntes e aplicações financeiras, determinações de bloqueio e desbloqueio de contas e comunicações de decretação e extinção de falência.

${ }^{15}$ A Lei n⿳a $11.419 / 2006$ regulamentou o Processo Eletrônico. O Tribunal Regional Federal da 4ํㅡㄹ Região foi o pioneiro na criação do e-proc. Por meio da Resolução n ${ }^{a}$ 13, de 11/03/2004, a Presidência do TRF4ºR, autorizou a implantação do processo eletrônico nos Juizados Especiais Federais da 4o Região, Turmas Recursais dos Estados do Paraná, Rio Grande do Sul e Santa Catarina e na Turma Regional de Uniformização da $4^{\circ}$ Região. O Provimento n⿳a 01, de 10 de maio de 2004, da Presidência do TRF4ํㅡ, estabeleceu normas complementares para a utilização do sistema.

${ }^{16}$ Disponível em http://www.cnj.gov.br/index. php?option=com_content\&task= view\&id=2663\&Itemid=251. Acessao em: 15 ago. 2007. 
constitui um meio relevante para a modernização da administração da justiça e para a sua democratização, a fim de acompanhar a dinâmica das relações econômicas e sociais dos novos tempos.

\subsection{Planejamento Estratégico em nível nacional}

São vários os fatores que impedem a democratização do Poder Judiciário e causam a sua ineficiência em atender com celeridade, adequação e justiça as demandas sociais que lhe são propostas. As propostas para a resolução dos problemas também são várias.

Entretanto, antes de tudo é preciso identificar as reais causas e as soluções viáveis, mediante o indispensável desenvolvimento de estudos técnicos e estatísticas profissionais, a fim de diagnosticar a situação atual dos órgãos judiciários. Além disso, é necessário um planejamento estratégico em nível nacional, dada a diversidade de tribunais nos pais, que somam o total de 91 (noventa e um), funcionando em compartimentos estanques com gestão administrativa e jurisdicional diversa um do outro.

O Min. Sálvio de Figueiredo Teixeira (2001, p. 4) ressaltou sobre a necessidade da existência de um órgão nacional de planejamento:

De igual intensidade, outrossim, é a ausência de um órgão nacional de planejamento, que poderia ser agregado ou não à própria escola. Órgão com funcionamento permanente, dotado de estrutura leve e eficiente, no qual o "achismo" seria substituído pela pluralidade de idéias e manifestações, onde as experiências bem sucedidas poderiam florescer e seria uma constante o diálogo com a comunidade, com os dirigentes, com os mais experientes e com as inteligências mais lúcidas e privilegiadas, onde se formulariam alternativas para o bom funcionamento e para a própria política judiciária em seu sentido mais nobre, a repensar o Judiciário como órgão estatal a serviço da Nação e da cidadania, ocupando-se, inclusive, de anteprojetos de lei, como no campo processual.

Efetivamente é preciso que seja elaborado um Planejamento Estratégico do Poder Judiciário em nível nacional, o que já foi reconhecido pelo CNJ - Conselho Nacional de Justiça, que assumiu essa missão, conforme se verifica no seu Relatório Anual do ano de 2006 (CNJ, 2006, p. 6):

A Constituição Federal de 1988 conferiu ao Conselho Nacional de Justiça a atribuição de elaborar Relatório Anual a ser remetido ao Congresso Nacional (artigo 103-B, § 4 , VII). O Relatório tem por objetivo descrever as atividades do Conselho, apresentar e analisar a situação do Poder Judiciário no País, propor as providências necessárias. As recomendações do Conselho representam um instrumento para a função de aprimoramento do autogoverno do Poder Judiciário. 
Morosidade do Pode Judiciário: prioridades para a reforma

Desse modo, este Segundo Relatório do Conselho Nacional de Justiça constitui mais um alicerce na construção de uma cultura de planejamento estratégico em nível nacional em torno do processo de Reforma do Judiciário inaugurado pela Emenda $\mathrm{n}^{\mathrm{a}}$. 45, de dezembro de 2005. O relatório 2006 apresenta a agenda de política judiciária para o biênio 2006-2008, os projetos desenvolvidos e os resultados obtidos pelo Conselho Nacional de Justiça em 2006.

$[\ldots]$

Nesse contexto, o Conselho Nacional de Justiça reafirmou, em 2006, sua missão institucional precípua de desenvolver o planejamento estratégico para o Poder Judiciário Nacional, minimizando o insulamento administrativo por meio de políticas judiciárias aglutinadoras. Por isso, o Conselho tem buscado estimular a comunicação e a troca de experiências de gestão inovadoras (boas práticas); incrementar parcerias internas entre os diferentes órgãos judiciais; e fomentar parcerias externas com instituições do sistema de justiça e atores sociais para o aprimoramento do sistema judiciário nacional. As "ilhas de excelência” do Poder Judiciário Nacional têm recebido destaque e divulgação.

Importante destacar no Relatório Anual do CNJ (2006) as recomendações de providências consideradas como prioritárias para o aprimoramento do serviço judiciário. As sugestões alcançam tanto o âmbito normativo quanto o administrativo e gerencial.

As recomendações visam a atingir alguns objetivos, entre eles: a) centralizar as estatísticas na base única Justiça em Números - gerida pelo Conselho Nacional de Justiça, como instrumento de gestão, transparência e avaliação de desempenho do sistema judiciário nacional; b) diminuir, de modo claramente perceptível para a sociedade brasileira, a morosidade do Judiciário por meio de uso intensivo de novas tecnologias; c) adotar "padrões de interoperabilidade" para integração dos sistemas de informação do Poder Judiciário nacional; d) implementar as providências necessárias para a instalação da informatização do processo (processo virtual); e) institucionalizar um novo modelo organizacional, a partir de uma cultura interna que ponha fim ao puro "gerenciamento da rotina", ao improviso e ao insulamento administrativo; f) adotar iniciativas que repercutam em favor dos direitos humanos e do acesso à Justiça, bem como do combate ao crime organizado, à impunidade e à violência urbana.

Portanto, o CNJ deve desenvolver o planejamento estratégico para o Poder

${ }^{17} \mathrm{O}$ trabalho do Conselho Nacional de Justiça $(\mathrm{CNJ})$ é de importância vital para a reforma judiciária nos planos da atuação administrativa e financeira e no controle ético-disciplinar. Sua missão institucional precípua é a formulação de políticas e estratégias nacionais para tornar o Sistema Judiciário mais eficiente e menos oneroso. 
Vera Lúcia Feil Ponciano

Judiciário Nacional ${ }^{17}$, minimizando o isolamento administrativo por meio de políticas judiciárias uniformes, inclusive mediante apoio e contribuição de todos os tribunais do país.

\section{CONCLUSÃO}

A ampliação ao acesso à justiça e a contemplação de novos direitos fundamentais na Constituição Federal de 1988, aliadas à evolução na área da ciência e da tecnologia a partir do século passado, geraram uma explosão de litigiosidade e o protagonismo do Poder Judiciário.

A estrutura do sistema judiciário, porém, não estava preparada para atender às novas demandas propostas, o que gerou uma insatisfação social com a prestação jurisdicional, especialmente no tocante à morosidade.

A questão da morosidade passou a ser discutida abertamente pelos três Poderes e pela sociedade em geral, ressaltando-se a existência de uma "crise" do Poder Judiciário e destacando-se a necessidade de sua reforma.

Muitos debatem acerca da questão, no entanto, não são baseados em estudos e estatísticas técnicas, apontando soluções superficiais e paliativas.

As reformas legislativas efetuadas não são suficientes para resolver o problema da ineficiência da atividade jurisdicional. Assim, é necessário pensar em mudanças na estrutura do próprio sistema, a fim de adaptá-lo à realidade social e econômica brasileira, selecionando-se algumas prioridades.

As prioridades passam pela necessidade de: a) redução do valor das custas processuais; b) investimentos em recursos humanos, tecnológicos e materiais e/ c) planejamento estratégico em nível nacional, a cargo do CNJ.

\section{REFERÊNCIAS}

BARBOSA, Claudia Maria. Poder Judiciário: reforma para quê?. Âmbito Jurídico, Rio Grande, n. 46, out. 2007. Disponível em http://www.ambito-juridico.com.br/ site/dex.php?n_link=revista_artigos_leitura\&artigo_id=2339. Acesso em: 31 out. 2007.

BOBBIO, Norberto. A Era dos Direitos. Trad. Carlos Nelson Coutinho. Rio de Janeiro: Campus, 1992.

CONSELHO NACIONAL DE JUSTIÇA (CNJ). Relatório anual 2006. [Brasília, 2006]. Disponível em: <http://www.cnj.gov.br/index.php?option=com_ content\&task $=$ view\&id=2663\&Itemid=251>. Acessao em: 15 ago. 2007.

DAKOLIAS, Maria. O setor judiciário na América latina e no caribe. Elementos 
Morosidade do Pode Judiciário: prioridades para a reforma

para reforma. Washington, D.C.: Banco Mundial, 1996. (Relatório Técnico n. 319). Disponível em: 〈http://www.sintrajufpe.org.br/documento.pdf〉. Acesso em: 29 ago. 2007.

ESCOLA NACIONAL DE FORMAÇÃO E APERFEIÇOAMENTO DE MAGISTRADOS (ENFAM). Fundamentação constitucional. Brasília, 2007. Disponível em: <http://www.amb.com.br/portal/docs/noticias/ enfam_sugestoes.pdf>. Acesso em: 30 ago. 2007.

FARIA, José Eduardo. Direito e justiça no século XXI. Texto apresentado no Seminário Direito e Justiça no Século XXI. Coimbra: Centro de Estudos Sociais, 2003.

FREITAS, Vladimir Passos de. Eficiência em pauta. Considerações sobre a administração da justiça. Consultor Jurídico. Disponível em: <http:// conjur.estadao.com.br/static/text/49944?display>. Acesso em: 9 nov 2006.

KOERNER, Andrei; MACIEL, Denise. Sentidos da judicialização da política: duas análises. Lua Nova, n. 57, p. 113 -133, 2002.

MORAES, Alexandre de. Direitos Humanos Fundamentais: teoria geral. 4. ed. São Paulo: Atlas, 2002.

MOREIRA. Helena Delgado Ramos Fialho. Poder Judiciário no Brasil. Crise de Eficiência. Curitiba/PR: Juruá, 2004.

NAVES, Nilson. Acesso à Justiça. Revista do Centro de Estudos Judiciários do Conselho da Justiça Federal, Brasília, n. 22, p. 5-7, jul./set. 2003.

. Direito e Tecnologias da Informação. Revista do Centro de Estudos Judiciários do Conselho da Justiça Federal, Brasília, n. 19, p. 6-8, out/dez. 2002.

SANTOS, Boaventura de Souza. Introdução à sociologia da Administração da Justiça. In: FARIA José Eduardo (Org.). Direito e Justiça: a função social do judiciário. São Paulo: Ática, 1997.

TARGA, Maria Inês de Cerqueira César. Diagnóstico das Escolas da Magistratura existentes no Brasil. Disponível em: <http://www.enm.org.br/docs/ diagnostico_escolas.pdf>. Acesso em: 7 ago. 2007.

TASSE, Adel El. A “Crise” no Poder Judiciário. A falsidade do discurso que aponta os problemas, a insustentabilidade das soluções propostas e os apontamentos para a democratização estrutural. Curitiba/PR: Juruá, 2004.

TEIXEIRA, Sálvio de Figueiredo. A formação do juiz contemporâneo. Disponível 
em: <http://www.cjf.gov.br/revista/numero4/artigo12.htm>. Acesso em: 1 maio 2007.

- A Reforma do Judiciário: Reflexões e prioridades. Consulex: revista jurídica, v. 5, n. 112, p. 37-39, set. 2001.

TESSLER, Marga Barth. A importância de modernizar a administração da Justiça. Revista do Tribunal Regional Federal $4^{\circ}$ Região, Porto Alegre, ano 12, n. 42, p. 13-86, 2001.

THEODORO JÚNIOR, Humberto. Celeridade e efetividade da prestação jurisdicional. Insuficiência da reforma das leis processuais. Revista de Processo, São Paulo, v. 30, n. 125, p. 61-78, jul. 2005.

ZAFFARONI, Eugénio Raúl. Poder Judiciário: crises, acertos e desacertos. São Paulo: Revista dos Tribunais, 1995. 